\title{
Antioxidant effects of flavonoids from Ceylon green tea on stroke: a biochemical and pharmacological study
}

By

Sherry Shan Hong Huang

Thesis submitted to the University of Sri Jayewardenepura for the award of the Degree of Doctor of Philosophy in Medical Sciences 2008

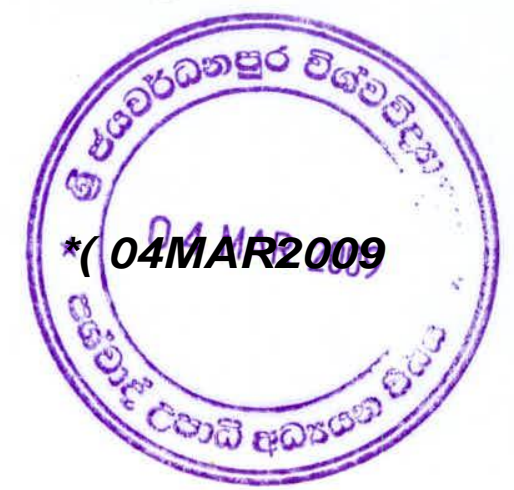


"The work described in this thesis was carried out by me under the supervision of Dr. Ranil De Silva and Prof. Yi Zhun Zhu and a report on this has not been submitted in whole or in part to any university or any other institution for another Degree."

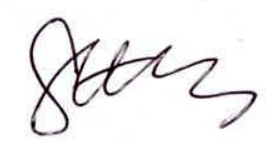

Sherry Huang Shan Hong 
"We certify that the above statement made by the candidate is true and that this thesis is suitable for submission to the University for the purpose of evaluation."

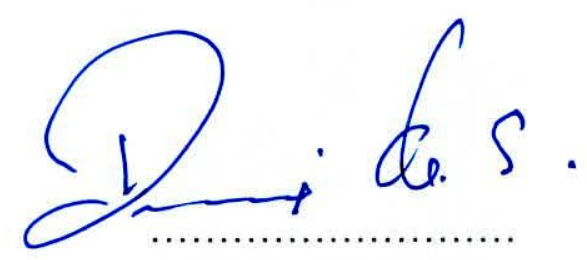

Dr. Ranil De Silva

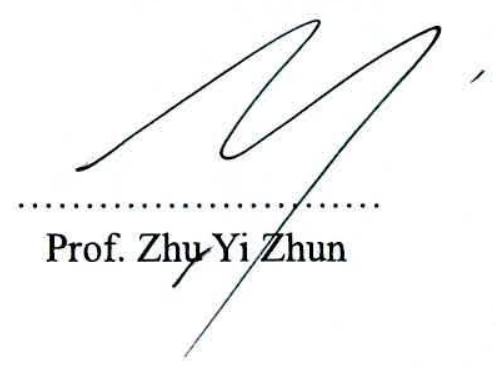




\section{TABLE OF CONTENTS}

TABLE OF CONTENTS

LIST OF FIGURES

VII

LIST OF TABLES

VIII

LIST OF PLATES

IX

LIST OF SYMBOLS / ABBREVIATIONS

XI

ACKNOWLEDGEMENTS

XIV

ABSTRACT

$\mathrm{XV}$

\section{CHAPTER 1: INTRODUCTION}

$1.1 \quad$ Stroke 1

1.2 Oxidative Stress in Ischemic Stroke 3

1.3 Formation of Reactive Oxygen Species (ROS) 6

1.4 Damaging effects of Oxidative stress and Reactive Oxygen

$\begin{array}{ll}\text { Species (ROS) } & 7\end{array}$

$\begin{array}{lll}\text { 1.5 Antioxidant Defense System in Cellular } & 10\end{array}$

1.6 Apoptosis can mediate cell death after hypoxia 13

1.7 Apoptosis, Necrosis and the Mitochondria 14

$\begin{array}{lll}1.8 & \text { Antioxidant } & 16\end{array}$

1.8.1 Principles and Pharmacology of Chinese green tea $\quad 17$

1.8.2 Flavonoids from Ceylon green tea 23

$\begin{array}{llr}\text { 1.8.3 Losartan } & 26\end{array}$ 
1.9 Non-enzymatic Antioxidants

1.9.1 Ascorbic Acid (Vitamin C) 29

1.9.2 Trolox (Vitamin E) 30

$\begin{array}{lll}1.10 & \text { Objective } & 36\end{array}$

CHAPTER 2: LITERATURE REVIEW

2.1 Background of traditional Chinese medicine and its use in Stroke Therapy

2.2 Antioxidants and their role in Ischemic Injury 38

2.3 Losartan and the roles of AT1R and AT2R in cerebral ischemia 39

CHAPTER 3: MATERIALS AND METHODS

3.1 MATERIALS

3.1.1 Green tea 41

3.1.1.1 Ceylon green tea $\quad 41$

3.1.1.2 Chinese green tea $\quad 41$

$\begin{array}{lll}\text { 3.1.2 Losartan } & 41\end{array}$

3.1.3 In vitro Antioxidant test 41

3.1.3.1 ABTS assay $\quad 41$

3.1.3.2 Pyrogallol Red assay $\quad 42$

3.1.4 Measurement of DNA damage 42 
3.1.5 Cell Culture 43

3.1.5.1 Cell line 43

3.1.5.2 Cell culture reagents 43

3.1.5.3 Antibodies 43

3.1.6 General Chemicals $\quad 44$

3.1.7 Instruments and Equipments 45

$\begin{array}{lll}3.2 & \text { Methods } & 45\end{array}$

3.2.1 Preparation of Flavonoids extract 45

3.2.2 Separation and isolation of lavonoids by HPLC 46

3.2.3 In Vitro Antioxidant Test 48

3.2.3.1 Inhibition of ABTS Assay 48

3.2.3.2 Inhibition of Pyrogallol Red Bleaching by Hypochlorous $\begin{array}{ll}\text { Acid }(\mathrm{HOCl}) & 49\end{array}$

3.2.4 Evaluation of DNA Damage using GC/MS 50

3.2.4.1 DNA Extraction from cell homogenate 51

3.2.4.2 Measurement of DNA damage using GC/MS 52

3.2.4.3 Acid Hydrolysis $\quad 52$

$\begin{array}{ll}\text { 3.2.4.4 Derivatisation } & 52\end{array}$

3.2.4.5 GC-MS Analysis $\quad 53$

$\begin{array}{lll}3.2 .5 & \text { Cell culture } & 54\end{array}$

3.2.6 Simulated hypoxia-induced ischemic model 55 
3.2.8 Evaluation of cell viability $\quad 59$

3.2.8.1 Trypan Blue Exclusion Viable Cell Counting $\quad 59$

3.2.8.2 Lactate Dehydrogenase (LDH) assay $\quad 60$

3.2.9 Total RNA isolation $\quad 62$

3.2.9.1 Homogenization and phase separation 62

3.2.9.2 RNA precipitation and quantitation 63

3.2.10 Reverse Transcription-Polymerase chain reaction (RT-PCR)64

3.2.10.1 Agarose Gel Electrophoresis $\quad 66$

3.2.11 Antioxidant Enzyme Activity Assay 67

3.2.11.1 Superoxide Dismutase Enzyme (SOD) Activity Test 68

3.2.11.2 Catalase Enzyme (CAT) Activity Test $\quad 70$

3.2.11.3 Glutathione-S-Transferase Enzyme (GST) Activity Test

3.2.11.4 Glutathione Peroxidase Enzyme (GPx) Activity Test72

3.2.11.5 Total protein assay 73

3.2.12 Immunohistochemical Staining 73

3.2.12.1 Sample preparation $\quad 73$

3.2.12.2 Antibody Staining $\quad 74$

3.2.12.3 Hematoxylin staining $\quad 76$

3.2.12.4 Mounting of Slides $\quad 76$

3.2.13 TUNEL (Terminal deoxynucleotidyl Transferase mediated 


\section{CHAPTER 4: RESULTS}

4.1 Biochemical Assays

4.1.1 Inhibition of ABTS Assay

4.1.2 Inhibition of Pyrogallol Red Bleaching by $\mathrm{HOCl}$

4.2 Evaluation of DNA Damage using GC/MS

4.3 The finger printing of flavonoids from Ceylon green tea obtained by HPLC

4.4 Cell viability

4.4.1 Trypan Blue Exclusion Assay

4.4.2 Lactate Dehydrogenase Assay

4.5 Antioxidant enzyme activity Assays

4.5.1 SOD (Superoxide dismutase enzyme activity) 90

4.5.2 CAT (Catalase enzyme activity) 92

4.5.3 GPx (Glutathione peroxidase enzyme activity) 93

4.5.4 GST (Glutathione-S-Transferase enzyme activity)

4.6 Gene expression of proteins involved in regulating apoptosis

4.6.1 Expression level of Bax

4.6.2 Expression level of Fas 99

4.6.3 Expression level of Asp53 100 
4.7 Immunohistochemical Staining result

4.8 TUNEL staining (Terminal deoxynucleotidyl Transferase mediated dUTP-Fluorescein Nickend Labeling) result

\section{Chapter 5: DISCUSSION}

5.1 Effect on in vitro Antioxidant Tests

5.2 Effect on DNA damage

5.3 Effect on cell viability and antioxidant enzyme activities

5.4 Effect on apoptotic Genes expression

5.5 Effect on immunohistochemical and TUNEL Staining

\section{Chapter 6: CONCLUSION}

CONCLUSION

PUBLICATIONS

REFERENCES 


\section{LIST OF FIGURES:}

Figure 1: $\quad$ Percentages and numbers of deaths worldwide in year $2002 \quad 2$

Figure 2: Ischemic Stroke and hemorrhagic stroke

Figure 3: Cellular mechanisms that may be involved in acute ischemia and $\mathrm{CNS}$ injury

Figure 4: Mechanisms of cell damage by oxidative stress

Figure 5: Conversion of guanine into 8-OH guanine

Figure 6: Endogenous antioxidant enzyme defense against oxidative stress 12

Figure 7: Chinese Green Tea

Figure 8: Structure of main active ingredients of catechin

Figure 9: Functional groups of catechin for antioxidant activity

Figure 10: Active position of catechins

Figure 11: A tea plantation in the Sri Lankan highlands

Figure 12: A plantation of Ceylon tea

Figure 13: The chemical structure of Losartan

Figure 14: The chemical structure of Vitamin C

Figure 15: The chemical structure of Vitamin E

Figure 16: Herbal extraction system

Figure 17: Flowchart of Flavonoids extraction from Ceylon green tea

Figure 18: Modular Incubator Chamber (MIC-101TM) for hypoxia

Figure 19: Cell morphology of HBEC in normoxic conditions

Figure 20: Cell morphology of HBEC in hypoxic conditions 
Figure 21: The conversion of NAD to NADH via LDH released from hypoxic cells

Figure 22: Preparation of cultured cell to Antioxidant Enzyme Activity Assay

\section{LIST OF TABLES:}

Table 1: The chemical composition of tea 24

Table 2: Groups for cell culture $\quad 55$

$\begin{array}{lll}\text { Table 3: } & \text { RT-PCR constituents } & 65\end{array}$

Table 4: $\quad$ Oligonucleotide sequences of primers used for RT-PCR 65

Table 5: Oxidized DNA base products were analyzed and quantified by GC/MS 


\section{LIST OF PLATES:}

Plate 1: $\quad$ Effects of ascorbic acid and various green tea extracts on TEAC values expressed as ascorbic acid equivalents

Plate 2: $\quad$ Effects of ascorbic acid and various green tea extracts on the inhibition of pyrogallol red (PR) bleaching by hypochlorous acid ( $\mathrm{HOCl}) \quad 83$

Plate 3: HPLC chromatograms of Ceylon green tea sample

Plate 4: Cells viability measurement using trypan blue exclusion of the normoxia, hypoxia, flavonoids treated, losartan treated and combined flavonoids and losartan treated groups with hypoxic conditions

Plate 5: Percentage of LDH release in normoxia, hypoxia, flavonoids treated, losartan treated and combined flavonoids and losartan treated groups with hypoxic conditions

Plate 6: Measurement of SOD activity in HBEC in normoxic control, hypoxic control, flavonoids treated and losartan treated groups in hypoxia

Plate 7: Measurement of CAT activity in HBEC in normoxic control, hypoxic control, flavonoids treated and losartan treated groups in hypoxia

Plate 8: $\quad$ Measurement of GPx activity in HBEC in normoxic control, hypoxic control, flavonoids treated and losartan treated groups in hypoxia

Plate 9: Measurement of GST activity in HBEC in normoxic control, hypoxic control, flavonoids treated and losartan treated groups in hypoxia

Plate 10: Gene expression level of Bax, Fas Asp53 and Bcl-2 and standardization of GAPDH

Plate 11: Effects of hypoxia and flavonoids treated and losartan treated groups with hypoxia on the gene expression levels of Bax

Plate 12: Effects of hypoxia and flavonoids treated and losartan treated groups with hypoxia on the gene expression levels of Fas

Plate 13: Effects of hypoxia and flavonoids treated and losartan treated groups 
Plate 14: Effects of hypoxia and flavonoids treated and losartan treated groups with hypoxia on the gene expression levels of Bcl-2

Plate 15: Effects of flavonoids treated and losartan treated groups on the state of cell via $\mathrm{Bcl}-2 / \mathrm{Bax}$ ratio

104

Plate 16: Light photomicrographs of HBECs after antibody (Bax, Fas Asp53 or Bcl-2) staining

Plate 17: Apoptotic staining in HBEC with hypoxia for different treatment groups 


\section{LIST OF SYMBOLS / ABBREVIATIONS:}

8-OHdG: 8-hydroxy-2'-deoxyguanosine

ABTS: 2,2'azinobis (3ethylbenothiazoline6sulfonic acid)

Bax: Bcl-2 associated protein $\mathrm{X}$

Bcl-2: B-cell chronic lymphocytic leukaemia/lymphoma 2

BSA: Bovine serum albumin

CVD: cerebrovascular disease

$\mathrm{Ca}^{2+}:$ Calcium

CAT: catalase

CO: Carbon monoxide

DAB: 3, 3' diaminutesobenzidine tetrahydrochloride

DEPC: Diethyl pyrocarbonate

DMEM: Dulbecco's Modified Eagle's Media with 25mM HEPES

DMSO: Dimethyl sulfoxide

DNA: Deoxyribonucleic acid

EDTA: Ethylenediaminetetraacetic acid

EGCG: epigallocatechin gallate

EGC: epigallocatechin

ECG: epicatechin gallate

EC: picatechin

EtBr: Ethidium bromide

FBS: Fetal bovine serum

GPx: glutathione peroxidase 
GST: glutathione-S-transferase

GSH: Glutathione

$\mathbf{H}_{2} \mathrm{O}_{2}$ : hydrogen peroxide

HCl: Hydrochloric acid

HBEC: human brain epithelial cells

HEPES: 4-(20hydroxyethyl)-1-piperazineethanesulfonic acid

HOCI: Hypochlorous acid

$\boldsymbol{K}$ : Rate constant

LDH: Lactate dehydrogenase

MI: Myocardial infarction

MIC-101TM: Modular Incubator Chamber

mRNA: Messenger ribonucleic acid

NADH: Reduced nicotinamide adenine dinucleotide

NO•: Nitric oxide

$\mathbf{N O}_{2}$-: Inorganic nitrite

NMDA: N-methyl-D-aspartate

NNDPD: N, N-dimethyl-p-phenylendiammonium

ODS: oxygen derived species

PLP: Pyridoxal 5'-phosphate

Pyrogallol red: pyrogallolsulphonephthalein

PBS: Phosphate-buffered Saline

PBS-Tx: Phosphate buffered saline-Triton X 
PKG: Protein kinase G

PSA: Antibiotic-Antimycotic Solution

ROS: reactive oxygen species

RNA: ribonucleic acid

SAM: S-adenosyl-L-methionine

SEM: Standard error of the mean

SOD: superoxide dismutase

SNP: Sodium nitroprusside

TEAC: trolox equivalent antioxidant capacity

Tris: Tris(hydroxymethyl)-aminomethane

TCA: Trichloroacetic acid

UK: United Kingdom

UV: Ultraviolet

WHO: World Health Organization 


\section{ACKNOWLEDGEMENTS}

I would like to extend my heartfelt appreciation to my project supervisor, Dr. Ranil De Silva and Prof. Zhu Yi Zhun, for allowing me to have the privilege to take up this interesting and challenging project and giving me the freedom to explore and plan my experiments. Both Dr. Ranil and Prof. Zhu have given me academic guidance and giving me a lot of encouragement through out my project, also given me constructive suggestions and invaluable advice.

I wish to extend my thanks and gratitude to Dr. T Amarakoon from Biochemistry Division, Tea Research Institute, Talawakelle, Sri Lanka who offered us all the wonderful tea materials and for being so supportive in this project.

Most importantly, I hope that my project can offer more knowledge and information to the existing research for the scientific usage of Ceylon green tea and treatment of patients suffering from ischemic cerebral diseases like stroke. Although what I have done is definitely a minor contribution for the scientific research in the field of cerebral vascular diseases. I hope that in the future, I would like to continue research work in this field and hopefully discover more potential active ingredients from Ceylon green tea to prevent stroke. 


\title{
Antioxidant effects of flavonoids from Ceylon green tea on
}

\author{
stroke: a biochemical and pharmacological study
}

\section{Sherry Shan Hong Huang}

\begin{abstract}
Stroke is one of the leading causes of death and long-time disability. In stroke, a reduced blood supply to the central system and the inadequate delivery oxygen to the brain results in hypoxia/ischemia. The flavonoids from Ceylon green tea (Dilmah) were extracted. In this project, an in vitro hypoxic model using Human Brain Epithelial Cells (HBEC) was studied with treatment of the tea extract before inducing hypoxia. We have tested the hypothesis that flavonoids from Ceylon green tea can reduce oxidative stress in hypoxic cells through its antioxidant properties and its ability to reduce cell death. The biochemical antioxidant tests showed that the Ceylon green tea has $68 \% \pm 2.8 \%$ inhibition property of scavenging of ABTS, similar to Chinese green tea: Qian Dao $(82 \% \pm 1.2 \%)$ and Bi Xue Chun $(80 \% \pm 1.2 \%)$. The Inhibition of Pyrogallol Red Bleaching by $\mathrm{HOCl}$ was examined too. The results also showed that Ceylon tea $(79 \% \pm 4.5 \%)$ has equal inhibiting property as Chinese green tea (Qian Dao $81 \% \pm 4.4 \%$ and Bi Xue Chun $83 \% \pm 3.3 \%$ ). Both DNA from Ceylon green tea treated hypoxic and control cells (without hypoxia) was extracted. Using GC/MS (Gas Chromatography/Mass Spectrometer), DNA base products were
\end{abstract}


measured. With flavonoids treated group showed significant lower level of total DNA base products damage $(1.13 \pm 0.42 \mathrm{nmol} / 100 \mu \mathrm{g}$ DNA) when compared to hypoxia group $(1.53 \pm 0.36 \mathrm{nmol} / 100 \mu \mathrm{g} \mathrm{DNA})$. The flavonoids were also analyzed by LC/MS (Liquid Chromatograph/Mass Spectrometer) to separate the compounds and identify the main compounds which might play an important role of antioxidant effect.

Losartan is one of the commonly used drugs with antioxidant effects to prevent further myocardial destruction. In the development of atherosclerosis, oxidation of low-density lipoprotein by free radicals is an important step. We compared Ceylon green tea (flavonoids) with it to demonstrate the antioxidant effects of Ceylon green tea.

The aim and objective of this project was thus to find out the in vitro antioxidant effects of flavonoids from Ceylon green tea on the cell viability of hypoxic human brain epithelial cells (HBEC), and measure the antioxidant enzyme activity and gene expression, including that of the proteins involved in apoptosis to compare with the Chinese green tea, as well as western drug (losartan).

Cell viability test was determined using trypan blue cell-exclusion method and lactate-dehydrogenase $(\mathrm{LDH})$ assay. Both showed that flavonoids treated group in hypoxia, the cell viability was $29 \% \pm 2.3 \%$ in the hypoxia control group but $41 \% \pm 4.7 \%$ for flavonoids treated group and $39 \% \pm 3.1 \%$ for losartan treated group. In LDH assay, flavonoids treated group had $75 \% \pm 3.7 \%$ reducing of LDH release and $79 \% \pm 3.5 \%$ in losartan treated group.

The flavonoids treated group significantly increased in antioxidant enzyme activity 
assays: the activity level of SOD $(1.5 \pm 0.6 \mu \mathrm{mol} / \mathrm{min} / \mathrm{mg}$ protein), CAT $(0.61 \pm 0.06 \mu \mathrm{mol} / \mathrm{min} / \mathrm{mg}$ protein $)$, GPx $(2.6 \pm 0.41 \mu \mathrm{mol} / \mathrm{min} / \mathrm{mg}$ protein $)$ and GST $(6.0 \pm 2.4 \mu \mathrm{mol} / \mathrm{min} / \mathrm{mg}$ protein) were significantly increased as compared with hypoxic control $(0.5 \pm 0.52,0.51 \pm 0.04,1.2 \pm 0.35$ and $3.1 \pm 1.6 \mu \mathrm{mol} / \mathrm{min} / \mathrm{mg}$ protein respectively). For the expression level of pro-apoptotic gene: Bax, Fas and Asp53, the result showed that the hypoxia cells after treatment, flavonoids treated group was significantly reduced the expression of the pro-apoptotic genes of Bax, Fas and Asp53. Meanwhile for the expression level of anti-apoptotic gene: Bcl-2, the result showed that the expression was stronger in flavonoids treated group when compared to hypoxia group. This would mean that the flavonoids from Ceylon green tea were able to reduce the amount of apoptosis after inducing hypoxia. Also, the expression levels of the pro-apoptotic genes were down-regulated and the expression of the anti-apoptotic gene was up-regulated, these would result in higher cell viability.

It also significantly reduced in immunoativities of the protein products of BAX (1.12 \pm 0.15 -fold), Fas (1.40 \pm 0.30 -fold), Asp53 (1.13 \pm 0.03 -fold) and Bcl-2 (0.88 \pm 0.08 -fold) when compared to hypoxia control (1.55 \pm 0.25 -fold, $1.66 \pm 0.20$-fold, $1.52 \pm 0.15$-fold and $0.61 \pm 0.13$-fold respectively). These results showed that pro-apoptotic proteins Bax, Fas and Asp53 have been detected dramatically more in hypoxia group, but less detected in flavoniods treated group. Weak signal of Bcl-2 was detected in hypoxia group and positive Bcl-2 staining was detected in hypoxia with flavonoids treated group. It indicated the down-regulation of pro-apoptotic proteins and up-regulation of anti-apoptotic protein during hypoxia. 
The least nuclear green fluorescence was observed in TUNEL staining assay, it indicated less apoptosis was found in flavonoids treated group as well.

The study demonstrated that frequently drink of Ceylon green tea is useful to prevent stroke. 